NASA

Technical Memorandum 106880

$$
\begin{aligned}
& N-37 \\
& 48306
\end{aligned}
$$

Army Research Laboratory Technical Report ARL-TR-760

\title{
Computerized Design and Generation of Low-Noise Gears With Localized Bearing Contact
}

Faydor L. Litvin, Ningxin Chen, Jui-Sheng Chen, and Jian Lu The University of Illinois at Chicago

Chicago, Illinois

Robert F. Handschuh

Vehicle Propulsion Directorate U.S. Army Research Laboratory

Lewis Research Center Cleveland, Ohio






\title{
COMPUTERIZED DESIGN AND GENERATION OF LOW-NOISE GEARS WITH LOCALIZED BEARING CONTACT
}

\author{
Faydor. L. Litvin, Ningxin Chen, Jui-Sheng Chen, and Jian Lu \\ The University of Illinois at Chicago \\ Chicago, Illinois 60607 \\ and \\ Robert F. Handschuh \\ Vehicle Propulsion Directorate \\ U.S. Army Research Laboratory \\ Lewis Research Center \\ Cleveland, Ohio 44135
}

\begin{abstract}
SUMMARY
The results of research projects directed at the reduction of noise caused by misalignment of the following gear drives: double-circular arc helical gears, modified involute helical gears, face-milled spiral bevel gears and face-milled formate cut hypoid gears are presented. Misalignment in these type of gear drives causes periodic, almost linear discontinuous functions of transmission errors. The period of such functions is the cycle of meshing when one pair of teeth is changed for the next. Due to the discontinuity of such functions of transmission errors high vibration and noise are inevitable. A predesigned parabolic function of transmission errors that is able to absorb linear discontinuous functions of transmission errors, and change the resulting function of transmission errors into a continuous one is proposed. The proposed idea was successfully tested using spiral bevel gears and the noise was reduced a substantial amount in comparison with the existing design.

The idea of a predesigned parabolic function is applied for the reduction of noise of helical and hypoid gears. The effectiveness of the proposed approach has been investigated by developed TCA (Tooth Contact Analysis) programs. The bearing contact for the mentioned above gears is localized. Conditions that avoid edge contact for the gear drives have been determined. Manufacturing of helical gears with new topology by hobs and grinding worms has been investigated.
\end{abstract}

\section{INTRODUCTION}

Vibration and noise of gears are caused by errors of gear alignment, and deflection of teeth and shafts under the load. The main attention in this paper is paid to the reduction of transmission errors caused by misalignment, and the stabilization of the bearing contact.

Gear misalignment and errors of manufacturing cause transmission errors that act as an oscillator of vibrations. Figure 1(a) shows the transmission function $\phi_{2}\left(\phi_{1}\right)$ for a misaligned gear drive. This function deviates from the theoretical transmission function $\phi_{2}^{(0)}\left(\phi_{1}\right)$ that is a linear one. The function of transmission errors $\Delta \phi_{2}\left(\phi_{1}\right)$ is represented as (fig. 1(b)).

$$
\Delta \phi_{2}\left(\phi_{1}\right)=\phi_{2}\left(\phi_{1}\right)-\phi_{2}^{(0)}\left(\phi_{1}\right)=\phi_{2}\left(\phi_{1}\right)-\frac{N_{1}}{N_{2}} \phi_{1}
$$

where $N_{i}(i=1,2)$ is the pinion 1 (gear 2) tooth number. Function $\Delta \phi_{2}\left(\phi_{1}\right)$ of transmission errors is a piecewise almost linear function with the frequency of the cycle of meshing determined by $\phi_{1}=\frac{2 \pi}{N_{1}}$. 
The shape of existing function of transmission errors shown in fig. 1(b) is very unfavorable because the transfer of meshing from one pair of teeth to the neighboring one is accompanied with a jerk of the teeth, and vibration and noise are inevitable. Since errors of misalignment cannot be avoided, we have to expect that the transformation of motions by a gear mechanism will be accompanied by transmission errors. However, although transmission errors cannot be avoided, there is a possibility to change the shape of the function of transmission errors to a more favorable one. This goal can be achieved by absorption of a linear function of transmission errors caused by misalignment by a predesigned parabolic function as shown in figure 2 . Figure 2(a) illustrates the interaction of two functions: (i) the linear function $\Delta \phi_{2}^{(1)}=b \phi_{1}$ caused by misalignment, and (ii) the predesigned parabolic function $\Delta \phi_{2}^{(2)}=-a \phi_{1}^{2}$. Function $\Delta \phi_{2}^{(2)}\left(\phi_{1}\right)$ is provided for the absorption of linear function $\Delta \phi_{2}^{(1)}\left(\phi_{1}\right)$. The resulting function $\Delta \phi_{2}\left(\phi_{1}\right)$ of transmission errors is represented as follows

$$
\Delta \phi_{2}\left(\phi_{1}\right)=\Delta \phi_{2}^{(1)}\left(\phi_{1}\right)+\Delta \phi_{2}^{(2)}\left(\phi_{1}\right)=b \phi_{1}-a \phi_{1}^{2}
$$

It is easy to verify that equation (1.2) represents in new coordinate system $\left(\Delta \psi_{2}, \psi_{1}\right)$ a parabolic function with the same parabola parameter $a$. The parabolic function (fig. 2(b)) is designated as

$$
\Delta \psi_{2}=-a \psi_{1}^{2}
$$

Axes of coordinate system $\left(\Delta \psi_{2}, \psi_{1}\right)$ and $\left(\Delta \phi_{2}, \phi_{1}\right)$ are parallel but the origins do not coincide. The coordinate transformation from $\left(\Delta \phi_{2}, \phi_{1}\right)$ to $\left(\Delta \psi_{2}, \psi_{1}\right)$ is represented with the following equations

$$
\Delta \psi_{2}=\Delta \phi_{2}-\frac{b^{2}}{4 a}, \psi_{1}=\phi_{1}-\frac{b}{2 a}
$$

The difference between functions $\Delta \phi_{2}\left(\phi_{1}\right)$ and $\Delta \psi_{2}\left(\psi_{1}\right)$ in addition to the change of location of the origin of coordinate system is the difference of location of points $(A, B)$ and the respective points $\left(A^{*}, B^{*}\right)$ (fig. 2(a)). The symmetrical location of $(A, B)$ is turned into asymmetrical location of $\left(A^{*}, B^{*}\right)$. However, the interaction of several functions $\Delta \Psi_{2}\left(\Psi_{1}\right)$ determined for several tooth surfaces being in mesh may provide a symmetrical parabolic function of transmission errors as shown in fig. 2(b). This can be achieved if the parabolic function $\Delta \phi_{2}\left(\phi_{1}\right)$ will be predesigned in the area (fig. 2(a)).

$$
\phi_{1}(B)-\phi_{1}(A) \geq \frac{2 \pi}{N_{1}}+2 c
$$

where $c=\frac{b}{2 a}$. The requirement of equation (1.5), if observed, permits a continuous function $\Delta \psi_{2}\left(\Psi_{1}\right)$ for the range of $\frac{2 \pi}{N_{1}}$.

The idea of a predesigned parabolic function for absorption of a linear function of transmission errors caused by gear misalignment have been applied for various types of gears in sections 2 to 6 of this paper. The application of a predesigned parabolic function of transmission errors requires modification of gear tooth surfaces.

The other ideas discussed in this paper, the localization of the bearing contact and its stabilization, are based on the following principals: (i) The instantaneous line contact of gear tooth surfaces is substituted by the instantaneous point contact; (ii) Due to elastic deformation, the real contact of gear tooth surfaces is spread over an elliptical area, and the bearing contact is formed as the set of instantaneous contact ellipses; (iii) The path of contact is chosen in the longitudinal direction, and the center of symmetry of the contact ellipse moves as well in the longitudinal direction; this makes the bearing contact more stable and, favors the conditions of lubrication. 


\section{INVOLUTE HELICAL GEARS WITH MODIFIED TOPOLOGY}

Preliminary Considerations.-Ideal involute helical gears are in line contact at every instant. The line of contact is the line of tangency to the helix on the base cylinder (fig. 3). The ideal gears perform rotation with constant gear ratio represented as

$$
m_{12}=\frac{\omega^{(1)}}{\omega^{(2)}}=\frac{r_{2}}{r_{1}}=\frac{r_{b 2}}{r_{b 1}}=\frac{N_{2}}{N_{1}}
$$

where $\omega^{(i)}(i=1,2)$ is the pinion (gear) angular velocity; $r_{i}$ is the radius of the operating pitch circle for nonstandard gears; $r_{i}=r_{p i}$, where $r_{p i}$ is the pitch circle, for standard gears; $r_{b i}$ is the radius of the base circle; $N_{i}$ is the tooth number. The gear axodes are cylinders of radii $r_{i}$, and the line of tangency of these cylinders is the instantaneous axis of rotation. The cross-section of the gear tooth surface is an involute profile (fig. 4(a)). The intersection of the tooth surface by a cylinder of radius $\rho$ is a helix (fig. 4(b)). The helix turns into a straight line when the cylinder is unrolled onto a plane (fig. $4(\mathrm{c})$ ). The lead $H$ represents the axial displacement for one revolution when a point moves along the helix. The lead $H$ of a helical gear is the same for a cylinder of any radius $\rho$, and can be expressed as follows (fig. 4(c))

$$
H=2 \pi \rho_{i} \tan \lambda_{\rho i}
$$

The screw parameter $p$ represents the axial displacement along the cylinder for the angle of one radian, and is represented as

$$
p=\frac{H}{2 \pi}=\rho_{i} \tan \lambda_{\rho i}
$$

Considering two mating helical gears and using equations (2.1) to (2.3), we obtain that the lead angles of the gears are equal only for helices on the gear cylinders $r_{1}$ and $r_{2}$, and $r_{b 1}$ and $r_{b 2}$. However, the mating gears for the case of external meshing have opposite directions of the helices. Equations (2.1) to (2.3) yield that

$$
\frac{H_{2}}{H_{1}}=\frac{N_{2}}{N_{1}}=m_{12}
$$

Existing Methods of Crowning.-The ideal helical gears are very sensitive to the angular errors of alignment such as crossing or intersecting of gear axes errors of lead angles and the profile angle of the tool. Such errors can cause an edge contact, and therefore the manufacturers used various methods of crowning of gear tooth surfaces to obtain a favorable localized bearing contact. The existing methods of crowning that have been observed reduce edge contacts but provide an undesirable shape of the function of transmission errors shown in figure 1(b), and vibration and noise of the gears are inevitable. This will be illustrated with two particular cases of crowning.

Case i: Crowning by modification of involute profiles:

Let us assume that the leads $H_{1}$ and $H_{2}$ are observed as the same as for ideal involute helical gears, and they are related with equation (2.4). The crowning is based on the modification of the involute profiles as shown in figure 5. The point of tangency $M$ of modified profiles is considered in the cross-section of the gear tooth surfaces. Point $M$ coincides with a current point of tangency of the ideal involute profiles. The normal at point $M$ to the theoretical and modified profiles is the same and passes through the instantaneous center of rotation $I$ (fig. 5 ). However, there is a big difference between the conditions of meshing of ideal involute helical gears and the gears provided with modified tooth surfaces, that can be described as follows: 
(i) The ideal involute helical gears are in line tangency at every instant. The modified involute helical gears are in point tangency at every instant.

(ii) The instantaneous point of tangency of modified gear tooth surfaces is point $M$ in the respective crosssection. In the process of meshing point $M$ moves along a straight line that passes through the current point $M$ and is parallel to gear axes.

(iii) The bearing contact is localized, and the path of contact is a helix on the cylinder of radius $O_{1} M$ for the pinion, and radius $\mathrm{O}_{2} \mathrm{M}$ for the gear.

(iv) The described method for crowning avoids edge contact of the gears, however, the function of transmission errors for the crowned gears has the unfavorable shape (fig. 1(b)). This is the reason why this method of crowning cannot be recommended for application.

Case 2: Crowning by modification of lead angle:

We will consider the following sub-cases:

(i) The profile modification, as described in case 1, is provided and in addition the lead angles are modified. The modified leads $H_{1}^{*}$ and $H_{2}^{*}$ satisfy equation (2.4). In this sub-case the main conditions of meshing are the same as in case 1, but there was not a need for modification of the lead angles.

(ii) The profile modification, as described in case 1, is provided but the modified leads $H_{1}^{*}$ and $H_{2}^{*}$ do not satisfy equation (2.4). In this sub-case the bearing contact is localized, the path of contact on the gear tooth surface is a helix, the line of action is a straight line that is parallel to the gear axis, but the gear ratio, although it is constant, differs from the theoretical one. The gear ratio is determined as

$$
m_{12}^{*}=\frac{H_{2}^{*}}{H_{1}^{*}} \neq \frac{N_{2}}{N_{1}}
$$

Since the real gear ratio $m_{12}^{*}$ differs from the theoretical one determined as $m_{12}=\frac{N_{2}}{N_{1}}$, the function of transmission errors has the shape shown in fig. 1(b), and the transformation of motion is accompanied by a jerk at each cycle of meshing.

(iii) The theoretical involute profiles are not modified, but the lead angles are changed, and $\frac{H_{2}^{*}}{H_{1}^{*}} \neq \frac{N_{2}}{N_{1}}$.

The contact of gear tooth surfaces is localized, and the path of contact on the gear tooth surface has the shape shown in figure 6. The disadvantage of such method of crowning is that the contact of gear tooth surface (due to small modification of leads) is close to the line contact, the gears are very sensitive to angular errors of misalignment, there is a possibility of an edge contact, and the function transmission errors has the unfavorable shape shown in figure 1(b).

New Approach for Modification of Gear Tooth Surfaces.-The existing methods of crowning discussed do not satisfy the requirements of the design and manufacture of low-noise helical gears with localized and stable bearing contact. The approach proposed in this paper is based on the following ideas:

1. The generation of gears is based on application of two imaginary rack-cutters, with surfaces $\Sigma_{t}$ and $\Sigma_{c}$, that generate the geartooth surface $\Sigma_{2}$ and the pinion tooth surface $\Sigma_{1}$, respectively. The normal sections of rackcutter tooth surfaces are shown in figures 7 (b) and (c). We may imagine that both rack-cutters are rigidly connected and generate the pinion and the gear simultaneously.

2. While the rack-cutters translate at the displacement $s_{C}$ (fig. 7(a)), the pinion is rotated on the angle

$$
\psi_{p}=\frac{s_{c}}{r_{p 1}}
$$


However, the gear is rotated through the angle

where $s_{t}=s_{c}$.

$$
\Psi_{g}=\frac{N_{\mathrm{p}}}{N_{g}}\left(\frac{s_{t}}{r_{p 1}}\right)-a\left(\frac{s_{t}}{r_{p 1}}\right)^{2}
$$

The observation of equation (2.7) provides a predesigned parabolic function with parabola parameter $a$. The predesigned parabolic function absorbs linear functions of transmission errors, and will substantially reduce the noise and vibration.

3. Due to deviation of rack-cutter surfaces $\Sigma_{c}$ and $\Sigma_{t}($ fig. $7(b))$, the gear tooth surfaces are in point contact at every instant, and the bearing contact is localized.

In reality, the finishing operations of the manufacture of the gears can be accomplished not by rack-cutters but by application: (a) of two grinding (cutting) worms, or (b) by form grinding. In the case of application of two worms, the following requirements must be observed:

(i) The surface of the grinding worm must be determined as the envelope to the family of surfaces of the respective rack-cutter.

(ii) The relations between the motions of the grinding worm and the pinion are represented by linear functions based on equation (2.6). However, the motions of the worm and the gear being generated are nonlinear functions whosederivation is based on equation (2.7) to provide a predesigned parabolic function.

In the case of form-grinding the respective requirements to be observed are as follows:

(i) The to-be-ground pinion surface is a helicoid. The tool is a disk-shaped wheel. The relative motion of the pinion (the grinding wheel) is the screw motion with the screw parameter $p$ of the helical gears. The required shape of the tool can be determined as described in (ref. 1).

(ii) All the above conditions must be observed when the gear is ground by the disk-shaped grinding wheel. In addition it is required that the tool will be plunged in the process of grinding in the direction of the shortest distance between the tool and the gear. The plunge of the tool must be varied and controlled in the process of grinding. The plunge is zero in the middle of the gear space, and maximum at the ends of the space. The varied plunge is required to provide the predesigned parabolic function of transmission errors.

(iii) Form-grinding requires the indexing of the pinion (gear) when the neighboring space is to be ground.

TCA computer programs have been developed to simulate the meshing and contact of the helical gears with the modified surface topology, and to investigate the influence of errors of angular misalignment. Through these programs the predesigned parabolic function has been shown to absorb the linear functions of transmission errors. The path contact on the gear tooth surface is stable, and slightly deviates from a helix for the misaligned gear drive. An example is shown in figure 8.

\section{DOUBLE CIRCULAR-ARC HELICAL GEARS WITH MODIFIED TOPOLOGY}

Preliminary Considerations. - The circular arc helical gears (N.-W.) have been proposed by Novikov (ref. 1) and Wildhaber (ref. 2). However, there is a significant difference between the ideas proposed by the above inventors. Wildhaber's idea is based on generation of the gears by the same imaginary rack-cutter that provides conjugate gear tooth surfaces being in line contact at every instant. Novikov proposed the application of two mismatched imaginary rack-cutters that provide conjugate gear tooth surfaces being in point contact at every instant. The great advantage of Novikov's invention is the possibility to obtain a small value of the relative normal curvature and reduce substantially the contact stresses. The weak point of Novikov's idea was the high bending stresses since the gear tooth surfaces are in point contact at every instant. The successful manufacturing of N.-W. gears has been accomplished by application of two mating hobs based on the idea of two mating imaginary rack-cutters. This idea has been proposed by Kudrjavtsev (ref. 3) in the former USSR and Winter and Looman (ref. 4) in Germany. 
The circular arc helical gears are only a particular case of a general type of helical gears which can transform rotation with constant gear ratio and are in point contact at every instant. Litvin (refs. 5 and 13) and Davidov (ref. 6) simultaneously and independently proposed a method of generation for helical gears by "two rigidly connected" tool surfaces. According to this idea, the generating surfaces may be rack-cutter surfaces, particularly. The kinematics of single circular arc helical gears was the subject of the paper by Litvin and C.-B. Tsay (ref. 7).

A substantial step forward in the design of N.-W. gears is the development of double circular arc helical gears with two zones of meshing. Such gears have been proposed in the former USSR (ref. 8) and the People's Republic of China (ref. 9). The geometry of such gears was discussed in reference 10. The main advantage of this development is the possibility to reduce the bending stresses while keeping the advantage of reduced contact stresses.

A great disadvantage of N.-W. gears, even with two zones of contact, is their noise. In the current investigation has shown that the noise results from the unfavorable shape of transmission errors of misaligned gear drives (fig. 1(b)). The above mentioned transmission errors cause high vibration and noise, and therefore such transmission errors must be avoided. A modified topology of gear tooth surface is proposed that will provide the predesigned parabolic function of transmission errors to absorb the linear functions of transmission errors caused by gear misalignment.

Generation of Pinion Gear Tooth Surfaces.-The imaginary process of generation of conjugate tooth surfaces is also based on application of two rack-cutters that are provided by two mismatched cylindrical surfaces $\Sigma_{t}$ and $\Sigma_{\mathrm{c}}$ as shown in fig. 9(a). The rack-cutter surfaces $\Sigma_{\mathrm{t}}$ and $\Sigma_{\mathrm{c}}$ are rigidly connected to each other in the process of the imaginary generation, and they are in tangency along two parallel straight lines, $a-a$ and $b-b$. These lines and the parallel axes of the gears form angle $\beta_{0}$, that is equal to the helix angle on the pinion (gear) pitch cylinder. The normal sections of the rack-cutters have been standardized in China (ref. 9) (fig. 10(a)) and in the former USSR (ref. 8) (fig. 10(b)). Rack-cutter surface $\Sigma_{\mathrm{c}}$ generates the pinion tooth surface $\Sigma_{\mathrm{p}}$, and the rack-cutter surface $\Sigma_{\mathrm{t}}$ generates the gear tooth surface $\Sigma_{\mathrm{g}}$.

It is obvious that due to the mismatch of the surfaces of the two rack-cutters, the generated tooth surfaces of the pinion and the gear will be in point contact at every instant. Each rack-cutter has two generating surfaces, located up and down with respect to plane $\Pi$ (fig. 9). Therefore, the pinion and the gear will be provided with two working surfaces, and two zones of point contact and meshing of the pinion-gear tooth surfaces will exist. Figure 11 shows the path contacts on the gear tooth surfaces.

The displacements of the rack-cutters and the angles of rotation of the pinion and the gear are related with equations (2.6) and (2.7) that guarantee the existence of the predesigned parabolic function of transmission errors. The finishing stage of generation for practical reasons uses grinding by worms or form-grinding. The design of the grinding tools is based on the principles discussed in section 2 .

\section{ANALYTICAL DETERMINATION OF TRANSMISSION ERRORS OF HELICAL GEARS CAUSED BY MISALIGNMENT}

Computerized analysis of meshing permits a determination of the transmission errors effect numerically. Our goals are: (i) to prove that the induced function of transmission errors is almost a linear one with respect to the rotation angle $\emptyset_{1}$ of the pinion(driving gear), and (ii) represent this function in terms of the errors of angular alignment and the gear design parameters. The approach proposed in references 10,13 , and 14 is used.

Assume that the tooth surfaces of an aligned gear drive are in tangency at a current point of the line of action. This line for the helical gears discussed above is almost a straight line that is parallel to the gear axes. Due to misalignment, the point of tangency of the theoretical tooth surfaces is displaced, and the surfaces interfere with each other or a lack of contact occurs. To restore the tooth surface contact, it is sufficient to provide a compensating turn of one of the mating gears, say gear 2 . The compensating turn $\Delta \phi_{2}$ can be determined by using the equation

$$
\left(\Delta \phi_{2} \times r_{2}+\Delta q\right) \cdot n=0
$$


Here: $\Delta \phi_{2}$ is the vector of the compensating angle of rotation of gear $2 ; \mathbf{n}$ is the unit normal at the contact point; $\mathbf{r}_{2}$ is the position vector of the current point of the line of action; $\Delta \mathbf{q}$ is the displacement of the contact point caused by misalignment.

Determination of Linear Functions of Transmission Errors Caused by Angular Errors. - Three types of angular misalignment are considered: crossing of axes, intersection of axes, and lead angle error of the pinion (or the gear).

Using equation (4.1), we have determined the following equation of transmission errors for both types of helical gears.

$$
\Delta \phi_{2}=b \phi_{1}
$$

where,

$$
b=\frac{N_{p}}{N_{g}} \tan \lambda_{p}\left(\Delta \gamma_{y}+\frac{\tan \alpha_{n}}{\sin \lambda_{p}} \Delta \gamma_{x}-\frac{\Delta \lambda_{p}}{\sin ^{2} \lambda_{p}}+\frac{\Delta \lambda_{g}}{\sin ^{2} \lambda_{g}}\right)
$$

Here: $\Delta \gamma_{x}$ is the crossing angle; $\Delta \gamma_{y}$ is the intersection angle; $\Delta \lambda_{p}$ and $\Delta \lambda_{g}$ are the lead angle errors of the pinion and gear, respectively.

Influence of Change of Center Distance.-The change of center distance of N.-W. gears and modified involute helical gears does not cause transmission errors but does shift of the bearing contact (the path of contact). The shift can be evaluated as the change of the pressure angle determined as follows:

(i) In the case of N.-W. gears we have (refs. 10 and 16)

$$
\sin \alpha_{\mathrm{n}}^{*}=\frac{\Delta \mathrm{E}-\mathrm{y}_{\mathrm{ot}}+\mathrm{y}_{\mathrm{oc}}}{\rho_{\mathrm{t}}-\rho_{\mathrm{c}}}
$$

where $y_{\text {or }}(r=c, t)$ is coordinate of circle center corresponding to circular $\operatorname{arc} \rho_{\tau}\left((r=c, t)\right.$ (fig. 4), $\alpha_{n}^{*}$ is the pressure angle in the normal section; $\alpha_{n}^{*}=\alpha_{n}$, where $\alpha_{n}$ is the nominal value of the, pressure angle, if $\Delta E$ (the change of the center distance) is equal to zero. The difference ( $\left.\alpha_{n}^{*}=\alpha_{n}\right)$ indicates the shift of the path of contact on the tooth surface(the bearing contact).

(ii) The influence of the center distance change in the case of modified involute helical gears, is represented by the equation

$$
\sin \alpha_{t}^{*}=\left(\sin ^{2} \alpha_{t}+\frac{2 \Delta E}{E} \cos \alpha_{t}\right)^{0.5}
$$

where $\alpha_{t}^{*}$ and $\alpha_{t}$ represent the transverse pressure angles for the center distances $(E+\Delta E)$ and $E$, respectively. The correctness of equations (4.2) to (4.5) has been confirmed by computations performed using TCA programs.

\section{HYPOID GEARS: INFLUENCE OF MISALIGNMENT AND REDUCTION OF TRANSMISSION ERRORS, STABILIZATION OF BEARING CONTACT}

Preliminary Considerations.-The geometry and generation of face-milled formate cut hypoid gear drives has been a subject of intensive research by several authors (refs. 13 and 15 to 18). A parabolic type of the function of transmission errors is provided at present by the controlled mismatch of gear tooth surfaces. Such a function, as it was explained above, is needed to counteract misalignment effects. The TCA evaluates the resulting transmission 
errors after the absorption of transmission errors caused by misalignment. Therefore, the question to be considered is what is the influence of each type of alignment error on transmission error function and the movement of the bearing contact. This question was answered in the investigation performed by reference 18 .

There is a possibility that an edge contact of the gear tooth surfaces of a hypoid gear drive will occur

(ref. 13) The edge contact means that the edge of one gear contacts the surface of the mating gear instead of ordinary contact of tooth surfaces. The edge contact in hypoid gear drives can be avoided with the proper direction of the path of contact on the gear tooth surfaces.

Influence of Misalignment-The proposed approach for investigation of the influence of misalignment on the transmission errors and the shift of the bearing contact is based on the following procedure: (i) Using the local synthesis method (ref. 13), a linear (or almost linear) transmission function is provided; (ii) Then, using the TCA method, the influence of the respective error of alignment is investigated. The results of a hypoid gear drive with $N_{1}=10, N_{2}=41$, diametral pitch $P_{d}=4.205$, are shown in figures 12 to 15 . The shift of the bearing contact caused by misalignment is shown in figure 16 . The results show that the errors of alignment will cause high vibration and noise, and a predesigned parabolic function for the absorption of transmission errors must be applied.

Perspective Hypoid Gear Drive.-There is a possibility to design and manufacture hypoid gear drives with reduced level of noise and a stable bearing contact. Figure 17 shows the bearing contact for a new design of a hypoid gear drive, that is formed by a contact ellipse that moves in the longitudinal direction. A predesigned parabolic function of transmission errors with the maximum of 6 arc seconds is provided to absorb the errors caused by misalignment.

\section{LOW-NOISE SPIRAL BEVEL GEARS}

The ideas discussed in this paper have been applied and tested for a new design of spiral bevel gears (refs. 19 and 20). The new design has been based on combination of the local synthesis method and TCA (ref. 13). The local synthesis method could provide improved conditions of meshing and contact at the mean point of tangency of gear tooth surfaces (ref. 13). A predesigned parabolic function of transmission errors was provided, and the maximum value of transmission errors was reduced a factor of three in comparison with the previous design. The obtained function of transmission errors and the bearing contact are shown in figure 18. The predicted type and level of transmission errors and the contact pattern were confirmed and the level of noise was reduced 12 to 18 decibels at the spiral level gear meshing frequencies (ref. 20).

\section{CONCLUSION}

The following conclusions can be drawn from the study conducted herein:

1. Transmission errors of involute helical gears, double circular-arc helical gears, and face-milled formate cut hypoid gears caused by misaligned have been determined.

2. Application of a predesigned parabolic function of transmission errors for reduction of vibration and noise has been illustrated.

3. Modification of surface topology of helical gears for reduction of noise has been proposed. The generation of helical gears with the new design can be accomplished by form-grinding (cutting) and grinding (cutting) by a worm-tool.

4. Application of the ideas for generation of spiral bevel gears and hypoid gears with improved criterion have been illustrated.

\section{REFERENCES}

1. Novikov, M.L.: USSR Patent No. 109, 750, 1956.

2. Wildhaber, E.: US Patent No.1, 601, 750 issued Oct. 5, 1926, and Gears with Circular Tooth Profile Similar to the Novikov System, VDI Berichte, no. 47, 1961.

3. Kudrjavtsev, V.N.: Epicycloidal Trains, Mashgis, 1966. 
4. Winter, H., and Looman, J.: Tools for Making Helical Circular Arc Spur Gears, VDI Berichte, no. 47, 1961.

5. Litvin, F.L.: The Investigation of the Geometric Properties of a Variety of Novikov Gearing, The Proceedings of Leningrad Mechanical Institute, 1962, no. 24 (in Russian).

6. Davidov, J.S.: The Generation of Conjugate Surfaces by Two Rigidly Connected Tool Surfaces, Vestnik Mashinostroyenia, 1963, no. 2.

7. Litvin, F.L. and Tsay, C.-B.: Helical Gears With Circular Arc Teeth, J. Mech Transm Auto Des, 107, 1985, pp. 556-564.

8. Kudrjavtsev, V.N.: Machine Elements, Mashgis, 1980.

9. Chinese Standard, J B 2940-81, 1981.

10. Litvin, F.L. and Lu, J.: Computerized Simulation of Generation, Meshing and Contact of Double Circular-Arc Helical Gears, Math. Comput. Modelling, 1993, pp. 31-47.

11. Litvin, F.L., Zhang, J., Handschuh, R.F. and Coy, J.J.: Topology of Modified Helical Gears, Surf. Topography, 2, 1989, pp. 41-58.

12. Litvin, F.L., Theory of Gearing: NASA Reference Publication 1212, 1989.

13. Litvin, F.L.: Gear Geometry and Applied Theory, Prentice Hall, 1994.

14. Litvin, F.L.: Theory of Gearing, (in Russian), 1st ed. in 1960, 2nd ed. in 1968.

15. Baxter, M.L.: Basic Geometry and Tooth Contact of Hypoid Gears, Industrial Mathematik, no. 2., 1961.

16. Gleason Works: Understanding Tooth Contact Analysis, Rochester, NY, 1970.

17. Litvin, F.L., and Gutman, Y.: Methods of Synthesis and Analysis For Hypoid Gear-Drives of Formate and Helixform, ASME J. Mechanical Design, vol. 103, pp. 83-113, 1981.

Part I.-Calculations for Machine Setting for Member Gear Manufacture of the Formate and Helixform Hypoid Gears, pp. 83-88.

Part II.-Machine Setting Calculations for the Pinions of Formate and Helixform Gears, pp. 89-101.

Part III.-Analysis and Optimal Synthesis Methods for Mismatched Gearing and Its Application for Hypoid Gears of Formate and Helixform, pp. 102-113.

18. Litvin, F.L., Chen, J.-S., Sep, T. M., and Wang, J.-C.: Computerized Simulation of Transmission Errors and Shift of Bearing Contact for Hypoid Gear Drive with Conjugate Gear Tooth Surfaces, presented at the ASME 1994 Design Automation Conference.

19. Litvin, F. L. and Zhang Y.: Local Synthesis and Tooth Contact Analysis of Face-Milled Spiral Bevel Gears, NASA Contractor Report 4342 (AVSCOM TR-90-C-028).

20.-Lewicki, D.G., Handschuh, R.F., Henry, Z.S., and Litvin, F.L.: Low-Noise, High-Strength, Spiral-Bevel Gears for Helicopter Transmissions, NASA TM-106080, AIAA-93-2149, Army Research Laboratory Memorandum Report ARL-MR-71. 


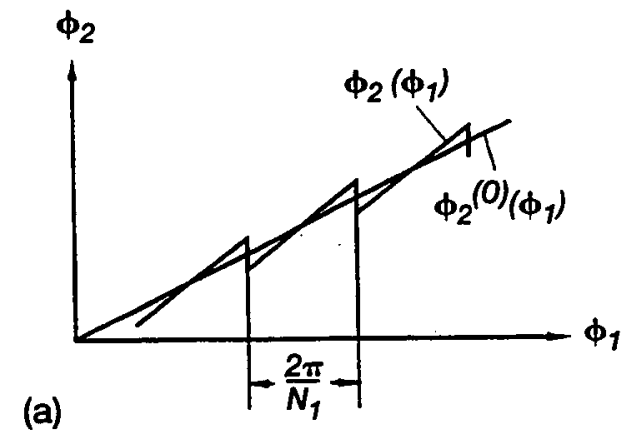

(a)

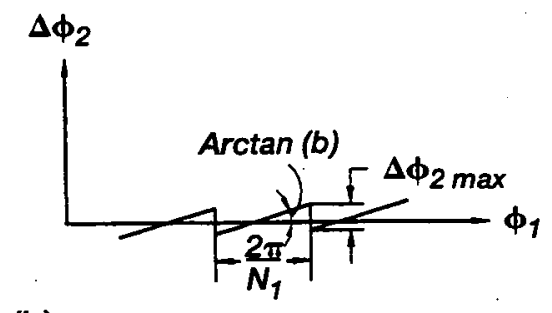

(b)

Figure 1.-Transmission function and transmission errors for a misaligned gear drive.

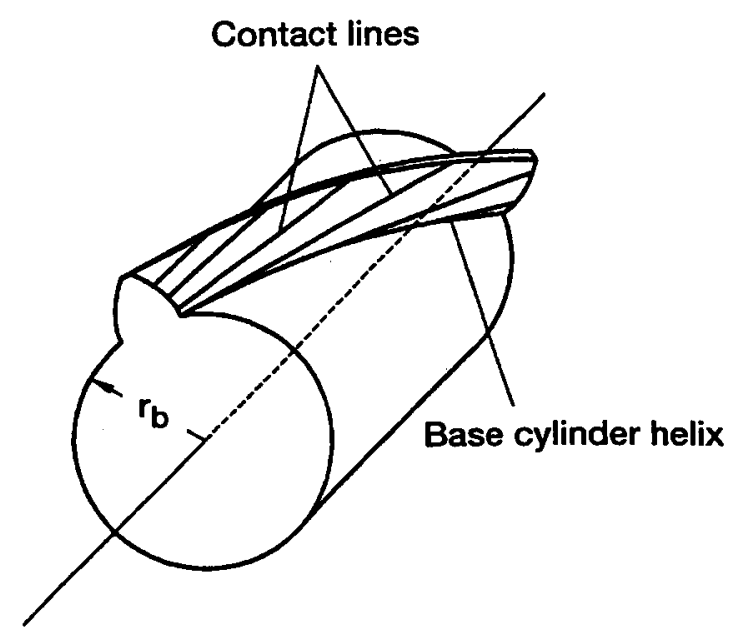

Figure 3.-Contact lines on tooth surfaces of an involute helical gear.
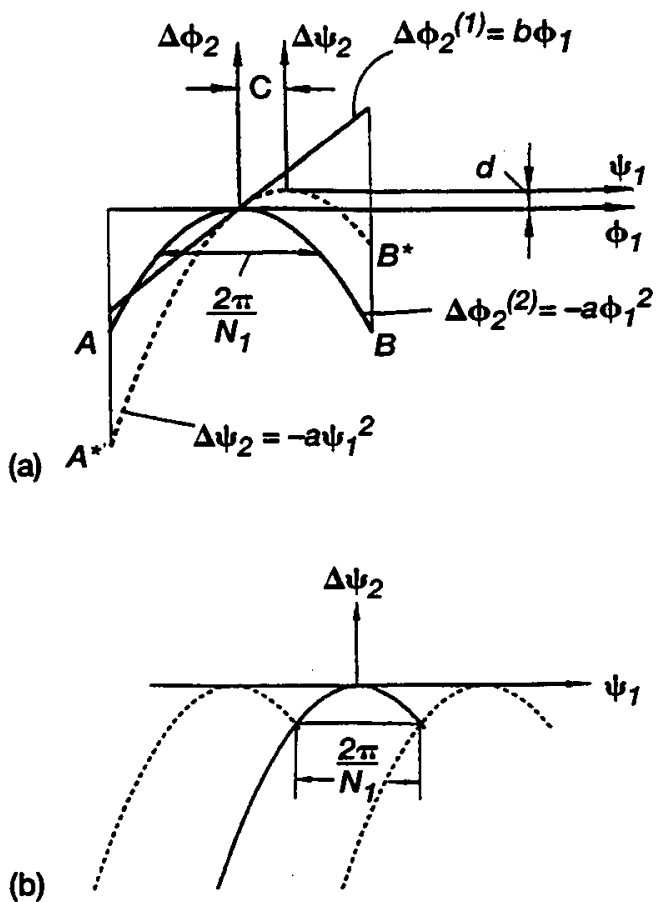

Figure 2.-Interaction of parabolic and linear functions.

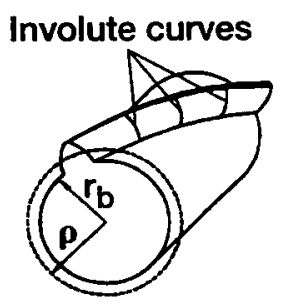

(a)
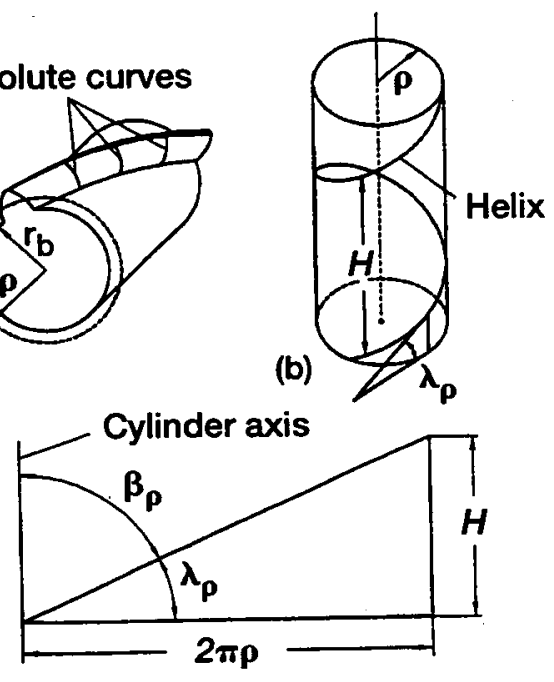

(c)

Figure 4.-Involute profiles of helical gear and development of a gear cylinder and its helix. 


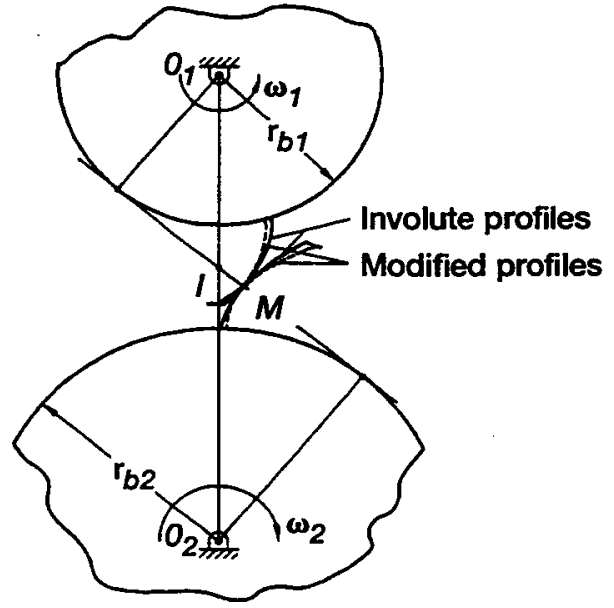

Figure 5.- Ideal and modified tooth profiles.

\section{Parallel to gear axis}

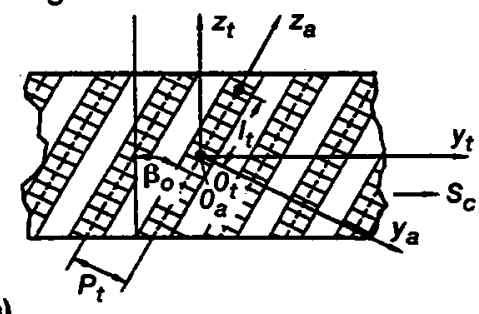

(a)

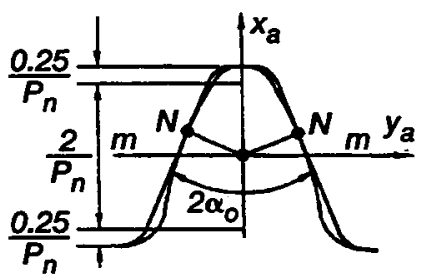

(b)

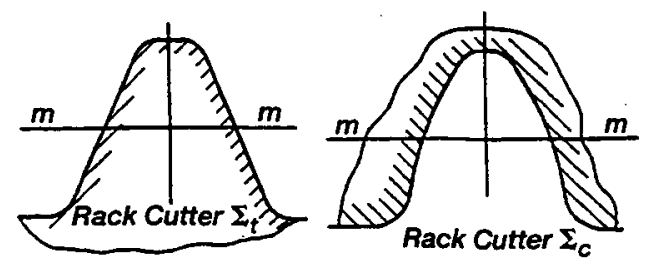

(c)

Figure 7.- Schematic of rack-cutters for generation of helical involute gears.
Pinion helix angle: $19^{\circ} 56 \mathrm{~m}$

Gear helix angle: $20^{\circ} 00 \mathrm{~m}$

Crossing angle of rotational axes: $4 \mathrm{~m} 0 \mathrm{sec}$

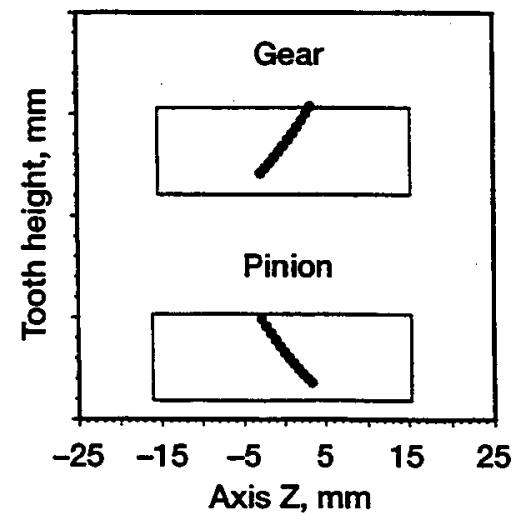

Figure 6.-Contact paths on gear tooth surfaces.



Figure 8. - Contact pattern for modified involute helical gears with misaligned axes $\left(\Delta \gamma_{\text {cross }}=-4\right.$ arc minutes). 


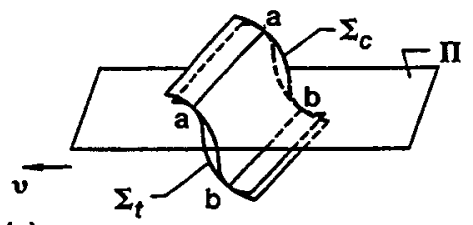

(a)

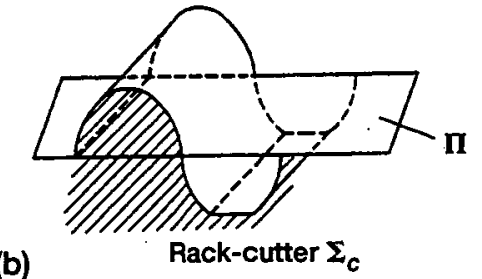

(c)

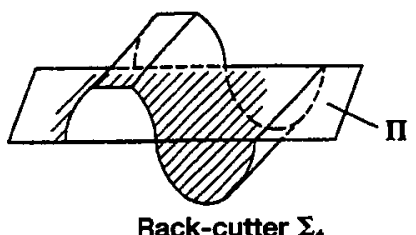

Figure 9.- Surfaces of imaginary rack-cutters for double circular-arc gears.

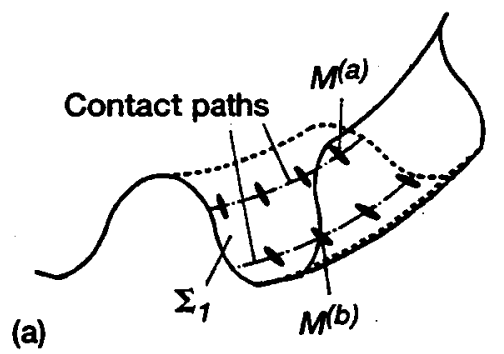

(a)



(b)

Figure 11. - Paths of contact and contact ellipses on pinion-gear tooth surfaces. (a) Pinion. (b) Gear.
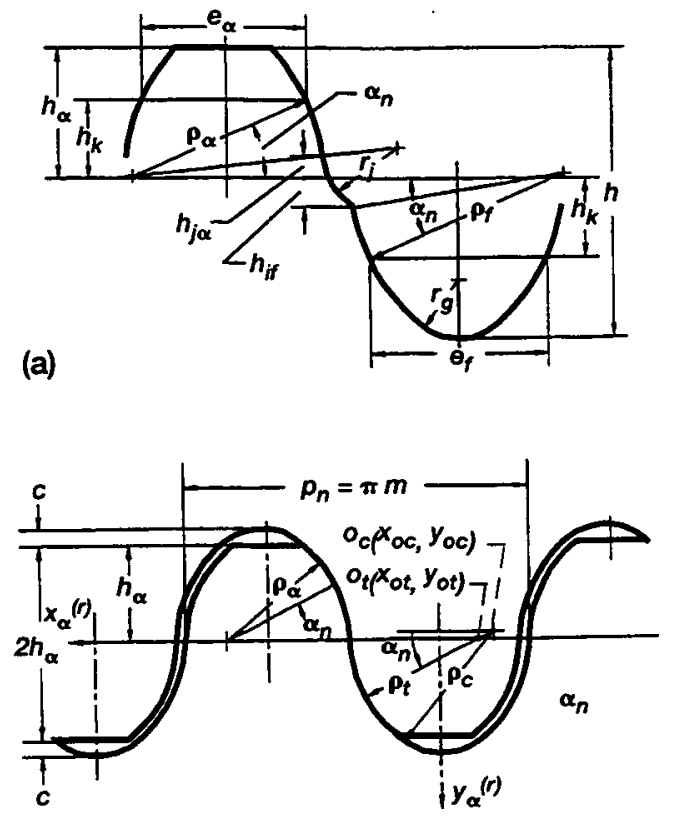

(b)

Figure 10.-Standardized rack-cutter profiles. (a) Chinese standard. (b) USSR standard.

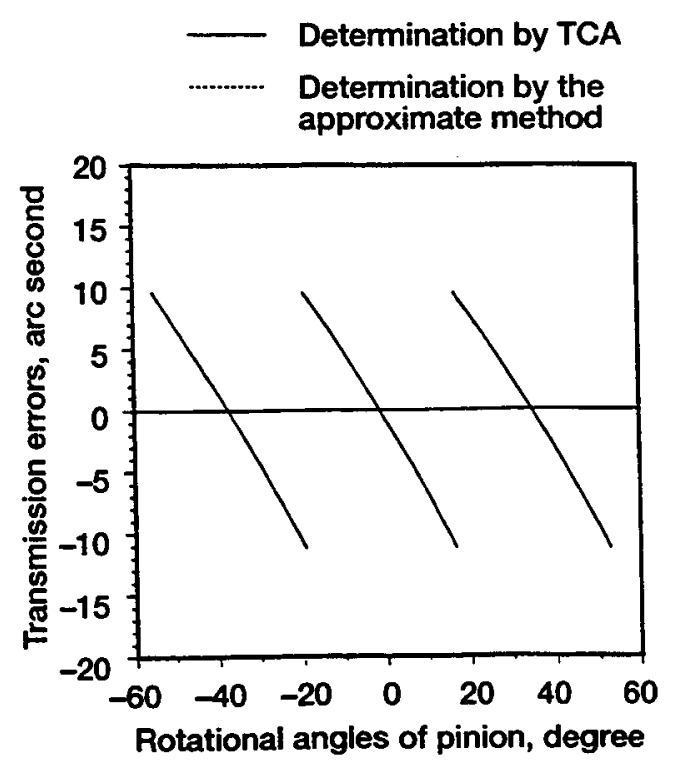

Figure 12.- Transmission errors caused by error of shaft angle $\Delta \alpha=0.3$ arc minutes. 


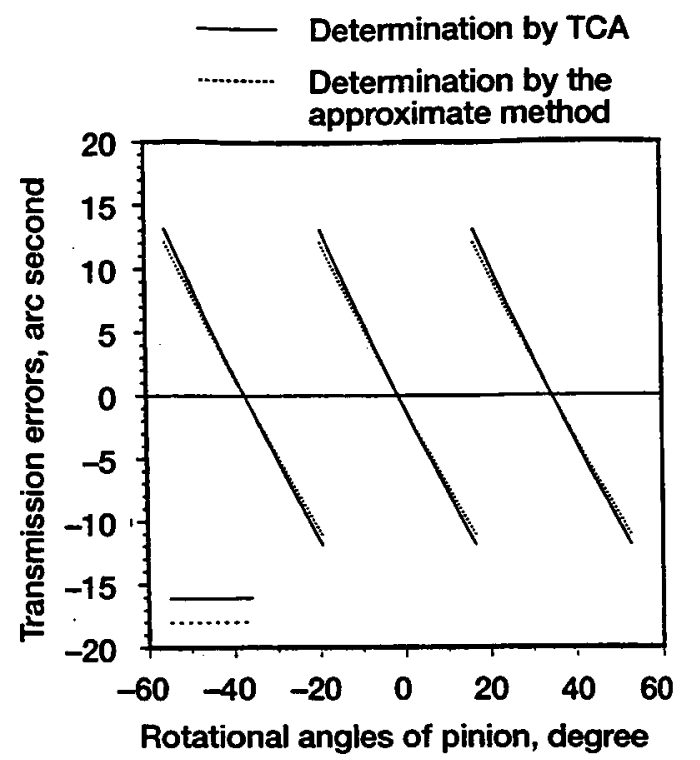

Figure 13.-Transmission errors caused by error of pinion offset $\Delta E=0.1 \mathrm{~mm}$.

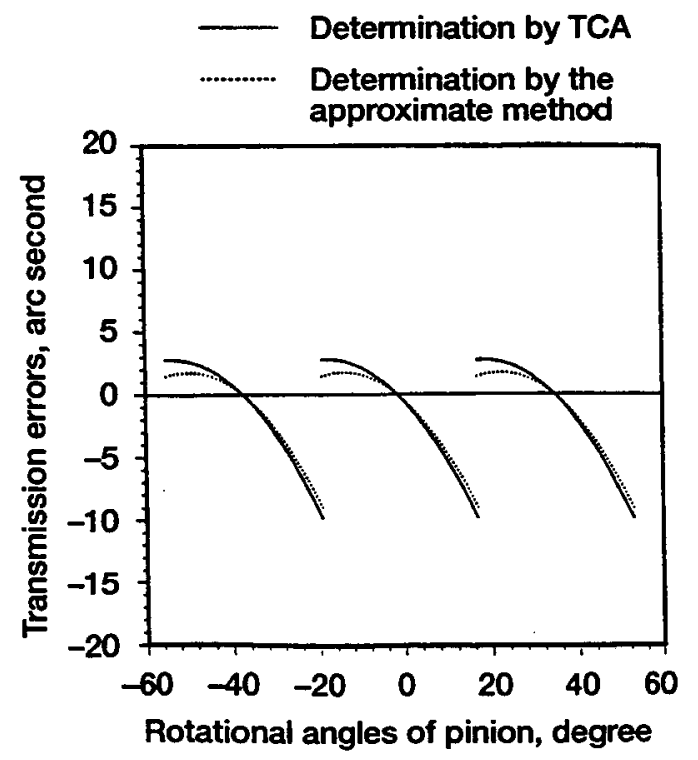

Figure 15.-Transmission errors caused by alignment error $\Delta G=0.1 \mathrm{~mm}$.

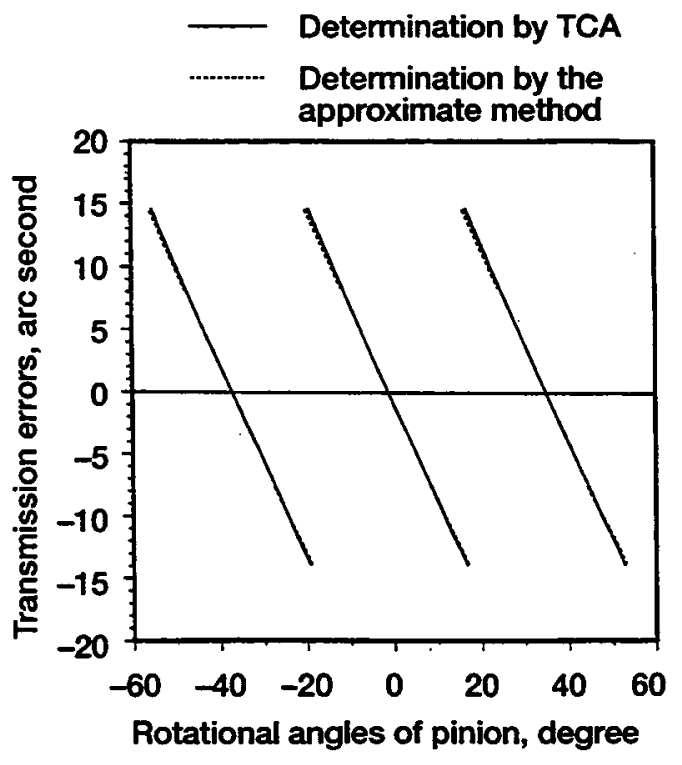

Figure 14.-Transmission errors caused by alignment error $\Delta P=0.1 \mathrm{~mm}$.

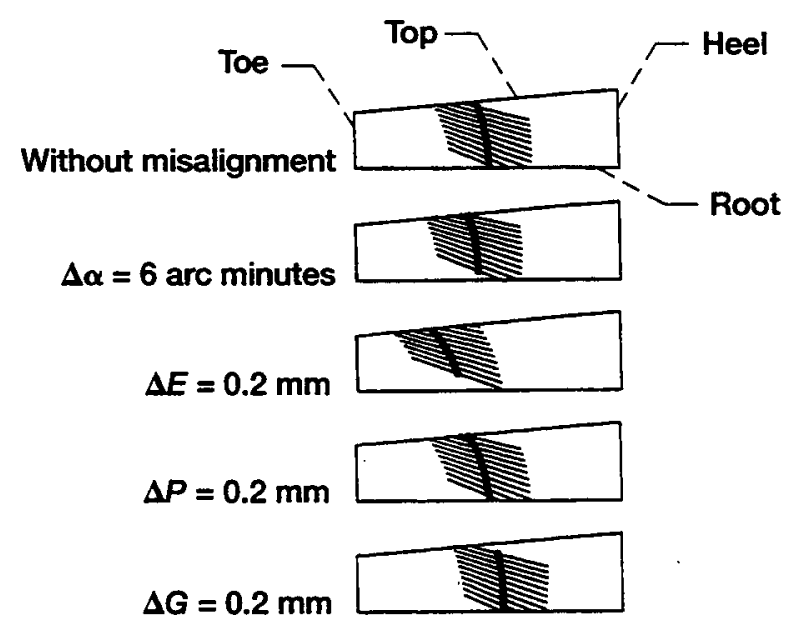

Figure 16. - Contact patterns for aligned and misaligned gear drives. 


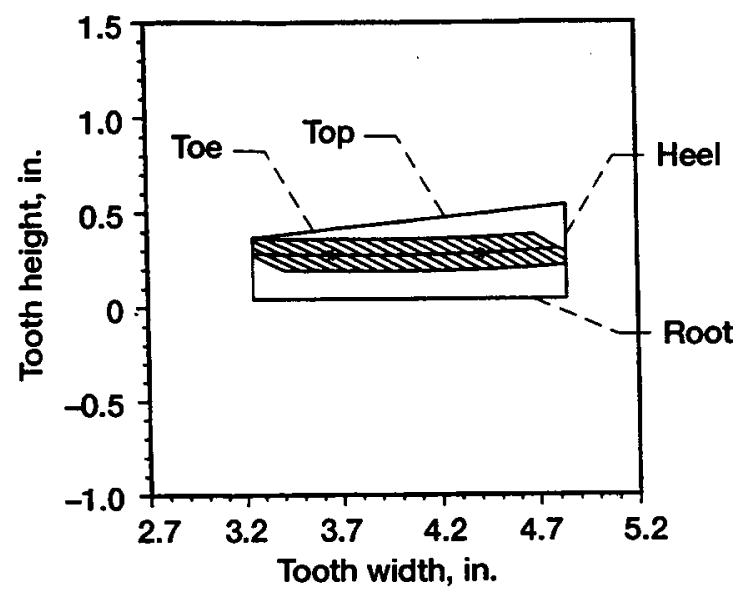

Figure 17.-Bearing contact for a new design of hypoid gear drive.
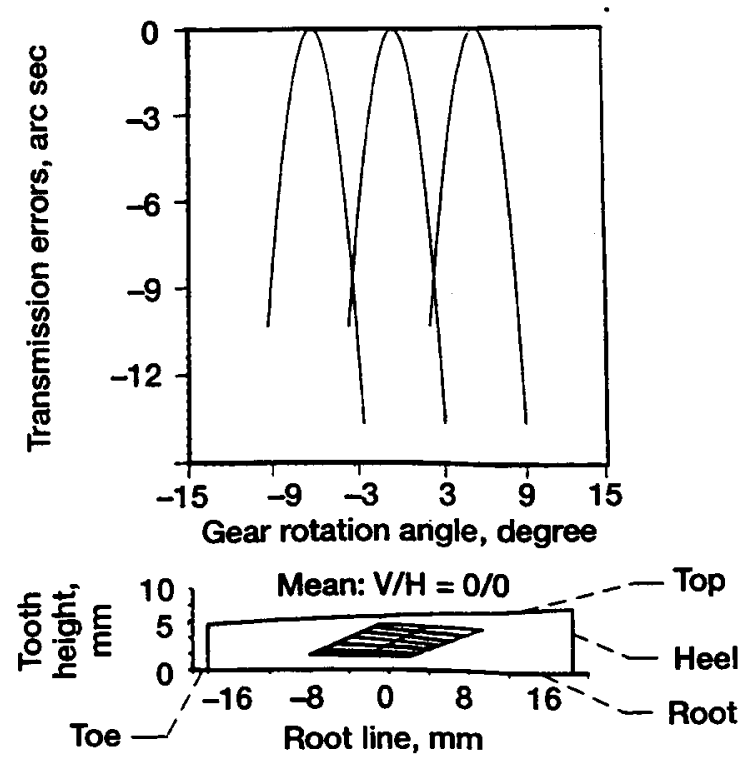

Figure 18.-Transmission errors and contact pattern for spiral bevel gears of new design. 
Public reporting burden for this collection of information is estimated to average 1 hour per response, including the time for reviewing instructions, searching existing data sources, gathering and maintaining the data needed, and completing and reviewing the collection of information. Send corrments regarding this burden estimate or any other aspect of this collection of information, including suggestions for reducing this burden, to Washington Headquarters Services, Directorate for Information Operations and Repons. 1215 Jefferson Davis Highway. Suite 1204, Arlington, VA 22202-4302, and to the Ottice of Managernent and Budget, Papenwork Reduction Project (0704-0188), Washington, DC 20503.

\section{AGENCY USE ONLY (Leave blank) \\ April 1995}

4. TITLE AND SUBTITLE
3. REPORT TYPE AND DATES COVERED

Technical Memorandum

Computerized Design and Generation of Low-Noise Gears With Localized Bearing Contact

6. AUTHOR(S)

Faydor L. Litvin, Ningxin Chen, Jui-Sheng Chen, Jian Lu, and Robert F. Handschuh

7. PERFORMING ORGANIZATION NAME(S) AND ADDRESS(ES)

NASA Lewis Research Center

5. FUNDING NUMBERS

Cleveland, Ohio 44135-3191

and

Vehicle Propulsion Directorate

U.S. Amy Research Laboratory

Cleveland, Ohio 44135-3191

WU-505-62-36

1L162211A47A

9. SPONSORING/MONITORING AGENCY NAME(S) AND ADDRESS(ES)

National Aeronautics and Space Administration

Washington, D.C. 20546-0001

and

U.S. Amy Research Laboratory

Adelphi, Maryland 20783-1145

8. PERFORMMNG ORGANIZATION REPORT NUMBER

E-9516

10. SPONSORING/MONITORING AGENCY REPORT NUMBER

NASA TM-106880

ARL-TR-760

11. SUPPLEMENTARY NOTES

Prepared for the 1994 Fall Technical Meeting sponsored by the American Gear Manufacturers Association, St. Louis, Missouri, October $24-28,1994$. Faydor L. Litvin, Ningxin Chen, Jui-Sheng Chen, and Jian Lu. The University of Illinois at Chicago, Chicago, Ilinois 60607, and Robert F. Handschuh, Vehicle Propulsion Directorate, U.S. Amny Research Laboratory, NASA Lewis Research Center. Responsible person, Robert F. Handschuh, organization code 2730, (216) 433-3969.

\begin{tabular}{l|l} 
12a. DISTRIBUTIONAVALABILTY STATEMENT & 12b. DISTRIBUTION CODE
\end{tabular}

Unclassified -Unlimited

Subject Category 37

This publication is available from the NASA Center for Aerospace Information, (301) 621-0390.

13. ABSTRACT (Maximum 200 words)

The results of research projects directed at the reduction of noise caused by misalignment of the following gear drives: double-circular arc helical gears, modified involute helical gears, face-milled spiral bevel gears and face-milled formate cut hypoid gears are presented. Misalignment in these types of gear drives causes periodic, almost linear discontinuous functions of transmission errors. The period of such functions is the cycle of meshing when one pair of teeth is changed for the next. Due to the discontinuity of such functions of transmission errors high vibration and noise are inevitable. A predesigned parabolic function of transmission errors that is able to absorb linear discontinuous functions of transmission errors and change the resulting function of transmission errors into a continuous one is proposed. The proposed idea was successfully tested using spiral bevel gears and the noise was reduced a substantial amount in comparison with the existing design. The idea of a predesigned parabolic function is applied for the reduction of noise of helical and hypoid gears. The effectiveness of the proposed approach has been investigated by developed TCA (Tooth Contact Analysis) programs. The bearing contact for the mentioned above gears is localized. Conditions that avoid edge contact for the gear drives have been determined. Manufacturing of helical gears with new topology by hobs and grinding worms has been investigated.

\begin{tabular}{|c|c|c|}
\hline \multicolumn{3}{|l|}{$\begin{array}{l}\text { 14. SUBJECT TERMS } \\
\text { Gears; Transmission }\end{array}$} \\
\hline $\begin{array}{l}\text { 17. SECURITY CLASSIFICATION } \\
\text { OF REPORT } \\
\text { Unclassified }\end{array}$ & $\begin{array}{l}\text { 18. SECURTYY CLASSIFICATION } \\
\text { OF THIS PAGE } \\
\text { Unclassified }\end{array}$ & $\begin{array}{l}\text { 19. SECURITY CLASSIFICATION } \\
\text { OF ABSTRACT } \\
\text { Unclassified }\end{array}$ \\
\hline
\end{tabular}

